\title{
COMER O PASSADO COMO PÃO DE FOME: RELAÇÕES ENTRE COMIDA E LITERATURA
}

\author{
Sabrina Sedlmayer \\ (Universidade Federal de Minas Gerais)
}

\begin{abstract}
RESUMO
A tematização da comida na literatura, além de se constituir como um campo investigativo vigoroso e potente, capaz de integrar e se relacionar a reflexões críticas acerca da memória, do espaço, da experiência, do corpo e das relações entre a tradição e a modernidade, permite abrir novas vias de estudo no que tange à apresentação da fome e da fartura em momentos literários diferenciados. Pretende-se cotejar, neste trabalho, textos literários que desenvolvam, de forma polarizada, a fome e a fartura (ou o banquete, o festim, a comezaina). As obras de Fernando Pessoa, Manuel de Freitas e Carlos de Oliveira, entre outros, serão lidas através do pensamento filosófico de Walter Benjamin, autor que reflexivamente escreveu sobre a comida e sua relação com a subjetividade e a memória.
\end{abstract}

PALAVRAS-CHAVE: fome, fartura, Literatura Portuguesa.

\section{ABSTRACT}

The thematization of the food, besides establish itself as a strong and powerful investigative field, able to integrate and relate to critical reflections regarding the memory, the space, the experience, the body and the relationships between tradition and modernity, allows to open new lines of study in relation to the presentation of hunger and abundance in different cultural, historical and literary moments. It is intended to compare, in this work, literary texts that develop, in a polarized fashion, hunger and abundance (or the banquet, the feast, the junketing). The works of Fernando Pessoa, Manuel de Freitas and Carlos de Oliveira will be read through the philosophical thinking of Walter Benjamin, author who reflectively wrote about the food and its relation to subjectivity and memory.

KEYWORDS: hunger, abundance, Portuguese literature. 


\section{METAMORFOSES}

Para Michel Serres, todo banquete deveria ter por título: sapiência e sagacidade. A comida, feita com chamas, fogos e fornos, seria resultado justamente dessa metamorfose:

Esta transformação, nas chamas, a passagem do cru ao cozido, tem a ver com o conhecimento. Fermentação do pão, ou do vinho, por exemplo, ou pré-transubstanciação. A Santa Ceia não consagrou a uva nem o trigo. Ela dá atenção às coisas comidas, degustadas, feitas, compostas, que o calor modificou. $\mathrm{O}$ vinho pertence à ordem do cozido: a cauda do pavão, onde cada ocelo destaca uma ilha simples da natureza, crua em sua composição elementar, reúne-se, organiza-se globalmente pela cocção (SERRES, 2001, p. 167).

Sócrates, Agatão, Alcibíades, Aristófanes, Aristodemo, entre outros convivas, em $O$ banquete, de Platão, participam de um encontro que discursa sobre o amor, a memória e, principalmente, sobre as transformações - caras ao procedimento literário - da mão em flor, de amante a amado. Se, pelo discurso de Sócrates, no banquete das palavras platônicas, a vida é celebrada, na Santa Ceia, como alude Michel Serres, é a morte que se torna matéria do conhecimento. Sabe-se que Claude Lévi-Strauss dedica um estudo a essa inflexão: do cru ao cozido. Tudo transformado, metamorfoseado, modificado pelo viés da comida.

Em A metamorfose, de Franz Kafka, a transformação de Gregor Samsa é logo seguida por uma alteração nas preferências alimentares:

Só depois de chegar à porta percebeu o que o tinha atraído para ela: o cheiro da comida. Com efeito, tinham lá posto uma tigela de leite dentro do qual flutuavam pedacinhos de pão. Quase desatou a rir de contentamento, porque sentia ainda mais fome que de manhã, e imediatamente enfiou a cabeça no leite, quase mergulhando também os olhos. Depressa, a retirou, desanimado: além de ter dificuldade em comer, por causa do flanco esquerdo magoado, que o obrigava a ingerir a comida à força de sacudidelas, recorrendo a todo o corpo, não gostava do leite, conquanto tivesse sido a sua bebida preferida e fosse certamente essa a razão que levara a irmã a pôr-lho ali. Efetivamente, foi quase com repulsa que se afastou da tigela e se arrastou até meio do quarto (KAFKA, 2001, p. 34).

Também no conto "O artista da fome”, de 1922, a temática é outra vez trabalhada por esse autor que acentua o processo de desvalorização da profissão, momento da modernidade no qual o povo perde o "interesse pelos artistas da fome".

Para Jean Anthelme Brillat-Savarin (1975), o destino das nações depende da maneira como elas cozinham. Inimigos foram feitos depois que Alexandre Dumas preparou um dicionário gastronômico para países que não sabiam o que era culinária (leia-se Espanha) e para todos os outros que 
nunca a tiveram. A grandiosidade da culinária francesa também foi cantada por Escoffier, chef dos chefs, que apontou como a força dessa cozinha se deve aos cuidados e às minúcias de quem a opera, de quem a conduz, para produzir, nos convivas, uma impressão sensorial plena. Sob o impacto da Segunda Guerra e a ocupação em terras francesas, temos também o relato de uma americana que se safou de escrever sua autobiografia ao sugerir trocá-la pela feitura de um livro de cozinha: Alice Toklas. Ela conseguiu convencer o editor ao, contundentemente, afirmar que livro de receitas é livro de memórias. Em 1948, data da primeira publicação do livro, a relação entre comida e memória pouco foi notada e passou despercebida. $\mathrm{O}$ alvoroço foi causado não pela perfeição dos relatos acerca da tradição francesa ou pelo cardápio da cena vanguardista, Picabia, Dali ou Picasso, mas muito mais pela receita de fudge de haxixe. Hoje, ao reler esse livro discreto, penso que talvez tenha sido um dos exemplos de escrita mais encharcados de memória e afeto que já se escreveu. Alice, ao cozinhar, escrevia para Gertrude. Outra americana - Elizabeth Bishop, que nasceu perto de Boston, mas se exilou em Minas Gerais e lá experimentou, como mostra Paulo Henriques Britto, o reencontro do lar perdido e a realização da paixão amorosa (BRITTO, 2012, p. 22) - também se viu às voltas com o processo de transformação. Ao traduzir o poema "A mesa", de Carlos Drummond de Andrade, sentiu-se emparedado pela questão das equivalências culinárias: como traduzir tutu, feijão tropeiro, torresminho?

Mais radical foi o gesto de Glauber Rocha: na conhecida tese-manifesto "Eztetyka da fome", de 1965, propõe transformar a fome em princípio capaz de provocar pensamento novo. Se a fome já fora tratada pelo Cinema Novo de modo político, estético, fenomenológico, demagógico, social, documental e cômico, aqui, via violência, convida-se à construção de uma cultura da fome intolerável e explosiva, mas passível de superação. Rastros do "Manifesto antropófago", de Oswald de Andrade, perpassam por aqui, além de se recuperar uma "galeria de famintos". Acredita-se, enfim, que "somente uma cultura da fome, minando suas próprias estruturas, pode superar-se qualitativamente: e a mais nobre manifestação cultural da fome é a violência" (ROCHA, 1965, [s.p.]).

\section{AMOR COMO DOBRADA FRIA}

Afastando-nos dessa cena brasileira que tematiza a fome, cuja motivação política é primordial, vale recuperar como a poesia de Fernando Pessoa, principalmente a de Álvaro de Campos, explora a relação da comida com o afeto de forma surpreendentemente inovadora. A frustração, a decepção com a não correspondência entre o prato pretendido e o prato servido encontra em "Dobrada à moda do Porto" uma figuração capaz de iluminar vários aspectos da poesia desse vanguardista queixoso. Aqui, a comida fria ${ }^{1}$ é relacionada à falta de amor. O tema "pobre velha casa da minha infância perdida", presente em "Esta velha angústia" e também em "Aniver- 
sário", reverbera e adquire outros contornos. Aspectos formais como o uso dos parênteses para falar sobre algo íntimo e confessional, como encontramos em "Tabacaria”, retornam nesses versos que falam do isolamento e da solidão daquele que come sozinho e espera, como em um quadro de Edward Hopper, o conforto de uma comida quente de outrora:

Um dia, num restaurante, fora do espaço e do tempo,

Serviram-me o amor como dobrada fria.

Disse delicadamente ao missionário da cozinha

Que a preferia quente,

Que a dobrada (e era a do Porto) nunca se come fria.

(PESSOA, 1992, p. 418)

A anacronia e a atopicidade do restaurante, acentuadas pela melancolia subjetiva, reforçam a cabal diferença com o passado, a "infância de toda gente onde houve jardim e brincadeiras", aquele "tempo em que festejavam o dia dos meus anos". A não conciliação entre o sujeito do presente e a infância de ontem, tempo jubilante, surge como uma espécie de ritornello, tema que insiste nos poemas escritos após a morte de Sá-Carneiro. Num gesto de síntese, pode-se afirmar que o verso de Campos capaz de resumir todas essas considerações realizadas até aqui seria: "Comer o passado como pão de fome, sem tempo de manteiga nos dentes!" (PESSOA, 1992, p. 379).

A avidez, a glutonia, o prazer do ato de sorver se encontrariam no passado (sem metafísica), na infância, quando era possível se fartar com um chocolate:

(Come chocolates, pequena:

Come chocolates!

Olha que não há mais metafísica no mundo senão chocolates.

Olha que as religiões todas não ensinam mais que a confeitaria.

Come, pequena suja, come!

Pudesse eu comer chocolates com a mesma verdade com que comes!

Mas eu penso e, ao tirar o papel de prata, que é de folha de estanho,

Deito tudo para o chão, como tenho deitado a vida.)

(PESSOA, 1992, p. 364)

A pequena suja se contrapõe àquele que teve a infância roubada quase como um jogo de luz e sombra, instinto e racionalidade, amor e carência. Álvaro de Campos, estrangeiro aqui como em qualquer parte - seja localizado na mansarda, seja no restaurante ou em qualquer rua da Baixa -, teima em se descrever como "o sem par no mundo" e, tal como o prato da dobrada, um fósforo frio. 


\section{VINHOS ESPESSOS, COPOS DE VIDRO GROSSOS}

Esse bebedor solitário, frequentador de tabernas e tascas baratas, encontra na contemporaneidade afinado diálogo com certo eu que se apresenta na poesia de Manuel de Freitas. Ao escrever versos prosaicos (com teor narrativo como o de Álvaro), num "país de restos de palavras" ou em uma "Terra sem coroa”, Portugal, cenários particulares como cafés, balcões, pubs e mesas prenhes de garrafas vazias de cerveja, uísque e vinho são configurados na poesia de Freitas.

Zulmira, Benilde, Noémia, Leirião se juntam a outras personagens "sem qualidades" (nome dado justamente à polêmica antologia organizada pelo autor em 2002, Poetas sem qualidades) em locais que sugerem comida e bebida e convocam à problematização acerca de uma ceno-grafia.

Lança-se a hipótese de que Freitas, reflexivamente, em suas atividades editoriais (fundou a editora Aveiro e publica, regularmente, livros de poesia desde 2002), ensaísticas e poéticas, trabalha justamente com a perda da aura e seu estatuto alegórico, conforme aponta Walter Benjamin. Valorizam-se reiteradamente os restos, os resíduos, as migalhas.

Rosa Maria Martelo já havia identificado que a obra poética de Freitas parece ser uma resposta a circunstâncias vivenciadas em lugares públicos. Observador ou interlocutor ocasional, o eu sempre sai de casa rumo às ruas. A crítica pontua a importância, a inflexão que parece ter ocorrido com o surgimento dessa poesia que marca uma "experiência de uma urbanidade agressiva e desestruturante das identidades pessoais" (MARTELO, 2010, p. 339). Percebe-se que a fome e a fartura se associam ao "onde" e ao "como", e a escrita aponta para uma espécie de ética, além de uma clara estética de matriz baudelairiana:

Ora associadas a espaços privados e fechados, como a casa ou o quarto, ora situadas em espaços abertos e públicos, como o café, a taberna ou mesmo a rua, ora diurnas, ora noturnas, as cenas de escrita nunca são inocentes. Muito pelo contrário, elas indicam sempre uma poética e também uma ética de leitura (MARTELO, 2010, p. 323).

O esforço de alegorização e certa promiscuidade boêmia perpassam essa poesia que localiza no "onde" da taberna dupla significação: salvação e perdição:

Errata

Onde se lê Deus deve-se ler morte.

Onde se lê poesia deve-se ler nada.

Onde se lê literatura deve-se ler o quêe?

Onde se lê eu deve-se ler morte.

Onde se lê amor deve-se ler Inês.

Onde se lê gato deve-se ler Barnabé.

Onde se lê amizade deve-se ler amizade. 
Onde se lê taberna deve-se ler salvação.

Onde se lê taberna deve-se ler perdição.

Onde se lê mundo deve-se ler tirem-me daqui.

Onde se lê Manuel de Freitas deve ser

com certeza um sítio muito triste.

(FREITAS, 2007, p. 38)

A negatividade parece ser o centro da poética de Freitas. O nada e a morte, pontos cardiais para a construção teórica acerca da dupla negatividade humana, respectivamente em Heidegger e Hegel, encontra, aqui, ecos baudelairianos. Nesse sentido, Freitas parece tecer uma ética comum com a teoria de Walter Benjamin no que tange ao declínio da aura. No prefácio da citada antologia Poetas sem qualidades, afirma:

O poeta aureolado, como observou Benjamin, adquiriu para o penetrante olhar baudelairiano um estatuto de "vieillerie". Por outras palavras, a partir de Baudelaire, a indissociabilidade entre o poeta e seu tempo adquiriu a força de uma evidência. O declínio da aura significa, entre outras coisas, o predomínio do temporal sobre o eterno e, concomitantemente, da prosa sobre o verso (FREITAS, 2012, p. 156).

A voz dos poemas de Freitas não distingue o eu do exercício de autoria. E o tempo encenado não corresponde à atualidade; como em Baudelaire, a essência das coisas é pura ruína.

\section{COMEZAINA: WALTER BENJAMIN}

Em Benjamin são inúmeras as passagens, nas mais variadas obras, cujas condições de produção alternam consideravelmente, em que a comida surge não apenas relacionada ao tema das viagens (viajo para conhecer a minha própria geografia, diria ele), dos costumes dos países e das cidades, da relação pessoal com o estrangeiro, como também atrelada ao menor, ao pormenor, ao detalhe, elementos absolutamente importantes para o olhar melancólico e materialista desse pensador e na obra de Freitas.

"Café creme", "Falerno e bacalhau", "Borscht, "Pranzo caprese", "Omelete de amoras", as mais variadas feiras com suas barracas de frutas, mariscos e ostras, os velhos cafés, os bistrôs e as pequenas cantinas, as porcelanas e o refinamento dos jantares da infância berlinense atravessam os escritos de forma sorrateira, mas reiterada e persistentemente. Imagens do pensamento que nos permitem especular como a comida possui um lugar em sua concepção de história e se encontra colada à lembrança de um tempo vivido. A força da madeleine permeia os escritos, mas não os esgota. Um lirismo, acoplado à falta de jeito do comensal (o corcundinha que ele era), encontra-se mesclado também a uma voracidade bulímica. Bulímico tanto no frequentar dos livros, no colecionar os livros, quanto no gesto de comer bem: 
Comer, isto significa antes de tudo: comer radicalmente. Não há dúvidas de que isso alcança mais profundamente a coisa devorada que o prazer. Por exemplo, quando alguém dá uma dentada na mortadela como se fosse pão, se chafurda no melão como numa almofada, lambe caviar de papel farfalhante e sobre uma cuia de queijo Edam se esquece de tudo o mais que existe na Terra para comer. - Como foi que eu soube disso pela primeira vez? (BENJAMIN, 1987, p. 213).

Para Benjamin, não deve haver parcimônia no ato de comer:

jamais provou uma iguaria, jamais degustou uma iguaria quem sempre a comeu com moderação. Assim se conhece talvez o prazer da comida, mas nunca a avidez por ela, o desvio do caminho plano do apetite, que leva à mata virgem da comezaina. É na comezaina, a saber, que estes dois se reúnem: a imoderação do desejo e a monotonia com que ele se sacia (BENJAMIN, 1987, p. 213).

Não é possível ignorar, ao ler tais excertos, os períodos de privação que o pensador dos limiares teve de enfrentar em sua vida após o avanço do totalitarismo na Europa. A maioria dos textos sobre comida foram justamente escritos em tempos de errância e fuga, muito provavelmente de fome, na Itália e em Ibiza. A avidez, a comezaina, o comer radicalmente se contrapõem ao tempo em que lia calmamente Proust, comendo marzipã. O que importa marcar é como a imoderação do desejo encontra ressonâncias na tentativa de articular o passado com o presente, destituído da ideia de acúmulo. Como em Freitas, realiza-se uma poética do inacabado, e a memória pessoal é espalhada pelos cantos como uma espécie de segredo.

\section{MESA, CASA E CHÃO: CARLOS DE OLIVEIRA}

Como vimos, a polaridade fome e fartura é tematizada nos escritos benjaminianos ${ }^{2}$ e encontra sensível ressonância na produção literária que venho tentando rastrear. Outro autor que elegeu o topoi da fome enlaçado às construções em madeira, orquestrado por uma escrita trabalhada que, para vários estudiosos, possui também, como em Freitas, esforço de alegorização, da passagem do símbolo à alegoria, é Carlos de Oliveira.

Na recepção crítica portuguesa, a ensaísta Silvina Rodrigues Lopes localiza a casa no centro da narrativa de Carlos de Oliveira e indaga: "Como é que o homem, personagem de Finisterra, organiza a sua experiência de memória através da casa em ruínas, experiência essa que constitui o motivo visível de narração?" (LOPES, 1996, p. 23). Oliveira, bem antes, já havia escrito sobre pobreza (o livro Mãe pobre é de 1945) e, em seu exercício poético, debruçado sobre a pobreza dos camponeses de Gândara.

O poeta Herberto Helder, em Edoi lelia doura, antologia que organizou em 1985, selecionou a obra de Carlos de Oliveira como uma das "vozes comunicantes" que intercepta e nutre sua própria oficina poética. 
Na nota biobibliográfica que elabora para apresentar o escritor como um dos representantes do que denomina "posse do encontro", diz:

Filho de portugueses, nasceu no Brasil, em Belém do Pará, em 1921, tendo vindo para Portugal ainda criança. Morreu em Lisboa em 1981. Livros de poemas: Turismo (1942), Mãe Pobre (1945), Colheita Perdida (1948), Descida aos infernos (1948), Terra de Harmonia (1950), Cantata (1960), Sobre o lado esquerdo (1968), Micropaisagem (1969), Entre duas Memórias (1971), Pastoral (1976), antologiados depois, e sempre rigorosamente corrigidos, nos 2 volumes de Trabalho Poético (1977 e 1978). Escreveu ainda romances. Finisterra (1978), proposto como romance, é antes uma alegoria ficcionalmente articulada que pode ser lida na perspectiva de uma espécie de cartografia imaginária do autor, constituindo assim a melhor introdução ou o melhor comentário à sua obra (HELDER, 1985, p. 170).

Temas helderianos são aqui também reconhecidos: a casa, a terra, a mãe, a criança, a memória, o lado esquerdo. Mas algo distancia Oliveira de Helder: o vínculo estreito com o Neorrealismo, a presença aguda do pensamento marxista, a reflexão sobre a pobreza e uma acirrada crítica à metafísica. Sabe-se que Carlos de Oliveira rompeu com concepções substancialistas acerca da miséria e de sua representação e ofereceu inquietas respostas pela via literária. Não fora, entretanto, o primeiro. Antes, já havíamos lido a Geração de 70, que combateu a imagem de Portugal-Império e o mito sebastianista. Eça de Queirós, Antero de Quental, Guerra Junqueiro, João de Deus, Teófilo Braga, entre outros, criaram uma veia irônica que ressoou, obliquamente, na prosa e na poesia de Carlos de Oliveira nos anos 1930, consolidando-se nos anos 1940 em torno da Revista Vértice. Se os primeiros liam Proudhon, Michelet e Darwin, o segundo grupo, o dos neorrealistas, buscava embasamento teórico e estético em Marx, na consciência de classe e em certa ética da representação.

O conceito de dialética é fundamental para o entendimento de Finisterra: paisagem e povoamento, cujo enredo, de difícil apreensão devido à quebra da linearidade cronológica e ao questionamento da representação tradicional, explora a suspensão do tempo presente, que se vê inundado por acontecimentos do passado. Farrapos, resíduos e, principalmente, reflexão acerca dos que pouco têm encontram lugar nessa escrita de "trabalho do fim" (GUSMÃO, 2009) e deixam pegadas:

Os camponeses, esses, destinados às sepulturas rasas, aos estratos de mortos sobre mortos, servem-se de pinho, dos adobes (materiais perecíveis), erguem casas na lama, manuseiam utensílios tão rudimentares como a charrua de madeira. Passam sobre a areia e as pegadas somem-se depressa, mas carregam aos ombros a pedra do meu lar (pensa a criança obscuramente) e a minha lápide futura (OLIVEIRA, 1968, p. 12). 
A precariedade, a fugacidade e a ausência de registro da existência alheia e a dor do outro são inscritos na obra de Oliveira. Em "Árvore", obscuramente assistimos ao rompimento das raízes na folha do livro que lemos:

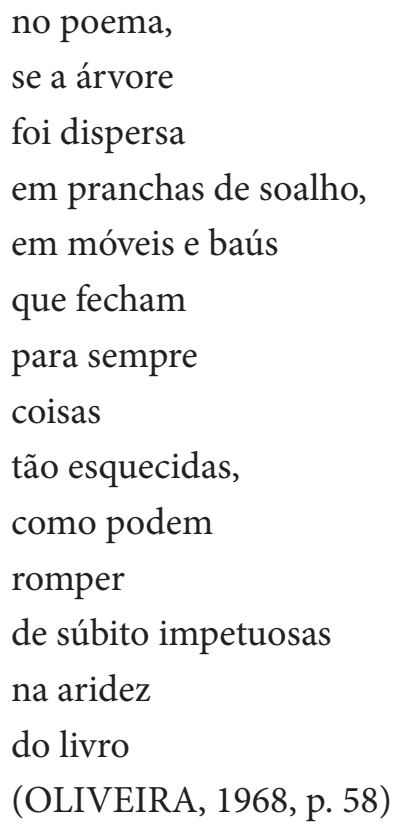

A materialidade das coisas, a composição dos móveis, surgem, assim, como chave de leitura capaz de iluminar outros exercícios poéticos que, obstinadamente, entrelaçam o tema da comida aos móveis de madeira como a mesa e o baú, como veremos a seguir

\section{COMIDA: PRE-TEXTO?}

No conhecido poema de Carlos Drummond de Andrade, "A mesa", há um verso precioso, que merece ser retido na conclusão deste ensaio: "Comíamos, e comer abria fome, e comida era pretexto" (DRUMMOND, 2002, p. 293). "Pretexto de quê?", poderíamos nos perguntar.

A rústica mesa mineira - local onde dramaticamente senta a fantasmagoria de Carlos, o gauche - é similar a uma mesa de cavalete, onde tudo expõe. Ou quase tudo. Importa lembrar que, no contexto mineiro, a mesa era considerada móvel de apoio. Destinada às refeições, possui uma particularidade entre todas as mesas, que a distingue e a singulariza: um ou mais pares de gavetas, escondidas abaixo do tampo, cujo propósito é esconder os pratos caso visitas cheguem, inadvertidamente, nas horas do repasto familiar.

Mas ser gauche na vida, estar ao lado esquerdo do pai, ${ }^{3}$ reúne, numa mesma colheita literária, o romance de Raduan Nassar, Lavoura arcaica, de 1975, e o amplifica:

O galho da direita era um desenvolvimento espontâneo do tronco, desde as raízes; já o da esquerda trazia o estigma de uma cicatriz, como se a mãe, que era por onde começava o segundo galho, fosse uma anomalia, uma protuberância 
mórbida, um enxerto junto ao tronco talvez funesto, pela carga de afeto; podia-se quem sabe dizer que a distribuição dos lugares na mesa (eram caprichos do tempo) definia as duas linhas da família (NASSAR, 1989, p. 156-157).

Podemos contrapor "A mesa" e Lavoura arcaica com a felicidade gustativa do conto "Peru de Natal", de Mário de Andrade. A sensualidade diante da volúpia que o sabor da ave suscita nos comensais suplanta o luto pelo pai morto. O domínio cinzento, sem lirismo, que era o do regime patriarcal, é combatido pelo filho, que influencia os convivas ao redor da mesa, na ceia de Natal, a comerem sem culpa.

O mesmo cardápio tropeiro apresentado na ceia do poema drummondiano aparece com riqueza de detalhamento na prosa de Pedro Nava:

$\mathrm{O}$ angu, que mole ou duro, combina-se com o feijão, com o arroz, com a carne e cujo único tempero deve ser o sal, assim mesmo pouco, para não alterar o gosto do que vai acompanhar. O que sobra é cortado em fatias que, fritas, são o pão mineiro de cada dia. O feijão fervido com bastante sal durante as paradas é levado em caixetas atulhadas e em cujos intervalos se escorreu a banha derretida que endurece e não deixa azedar a massa cozida. Na hora, vai tudo para a frigideira, a banha derrete-se, solta e refoga as pevides com mais a cebola, o alho, o cheiro verde, a salsa e a pimenta. Rola-se a farinha que se embebe de gordura, mas que não pode ficar empapada - antes móvel, toda untada e desgrudada. Come-se o ovo frito, a linguiça frita, o lombo frito e o torresmo totêmico. Repete-se antes da acabar. Parece fuga de Bach. É de chorar... (NAVA, 2012, p. 153-154).

Comenta-se e se comemora ao redor da mesa. Reconhecemos os lugares, mesmo os dos ausentes. Evocamos a primeira ceia: Tiago, João, Mateus. Também lembramos que comemorar é memorizar em comunhão, em conjunto. É preciso fazer reunião para nos lembrarmos, refazer e repetir os gestos. Nesse sentido, a voz de Campos, Freitas, Benjamin e Oliveira discorrem sobre a comida como um singular dispositivo contra o esquecimento ao permitir escoamento, passagem para lembrança.

\section{REFERÊNCIAS BIBLIOGRÁFICAS}

ANDRADE, Carlos Drummond de. A mesa. In: ANDRADE, Carlos Drummond de. Poesias completas. Rio de Janeiro: Nova Aguilar, 2002. p. 292-300.

ANDRADE, Mário de. O peru de Natal. In: Contos novos. São Paulo: Klick, 1997.

BENJAMIN, Walter. Imagens do pensamento. Edição e tradução de João Barrento. Lisboa: Assírio \& Alvim, 2004. 

- Rua de mão única. Trad. de Rubens Rodrigues Torres Filho e José Carlos Martins Barbosa. São Paulo: Brasiliense, 1987. (Obras escolhidas II).

BRITTO, Paulo Henriques. Elizabeth Bishop: os rigores do afeto. In: BISHOP, Elizabeth. Poemas escolhidos. Seleção, tradução e textos introdutórios de Paulo Henriques Britto. São Paulo: Companhia das Letras, 2012. p. 13-30.

BRILLAT-SAVARIN, Jean Anthelme. Physiologie du goût. (Avec une lecture de Roland Barthes). Paris: Hermann, 1975.

FREITAS, Manuel. Terra sem coroa. Lisboa: Teatro de Vila Real, 2007. . O tempo dos puetas. In: . Pedacinhos de ossos. Lisboa: Averno, 2012. p. 151-160.

GUSMÃO, Manuel. Finisterra - O trabalho do fim: reCitar a origem. Coimbra: Angelus Novus, 2009.

HELDER, Herberto (Org.). Edoi lelia doura: antologia das vozes comunicantes da poesia moderna portuguesa. Lisboa: Assírio \& Alvim, 1985.

KAFKA, Franz. A metamorfose seguida de O veredicto. Trad. de Marcelo Backes. Porto Alegre: L\&PM, 2001.

LOPES, Silvina Rodrigues. Carlos de Oliveira: o testemunho inadiável. Sintra: Câmara Municipal de Sintra, 1996.

MARTELO, Rosa Maria. A forma informe: leitura de poesias. Lisboa: Assírio \& Alvim, 2010.

NAVA, Pedro. Baú de ossos. São Paulo: Companhia das Letras, 2012.

NASSAR, Raduan. Lavoura arcaica. 3. ed. rev. pelo autor. São Paulo: Companhia das Letras, 1989.

OLIVEIRA, Carlos de. Finisterra: paisagem e povoamento. Lisboa: Assírio \& Alvim, 2003.

. Trabalho poético. Segundo Volume. Lisboa: Livraria Sá da Costa, 1968.

PESSOA, Fernando. Obra poética. Rio de Janeiro: Editora Nova Aguilar, 1992.

ROCHA, Glauber. Uma estética da fome. Resenha do Cinema Latinoamericano. 1965. Disponível em: http://www.tempoglauber.com.br/t_estetica.html. Acesso em: 30 nov. 2013.

SERRES, Michel. Os cinco sentidos: filosofia dos corpos misturados. Trad. de Eloá Jacobina. Rio de Janeiro: Bertrand Brasil, 2001. 
SEDLMAYER, Sabrina. Ao lado esquerdo do pai. Belo Horizonte: Editora UFMG, 1997.

Posfácio. In: NASSAR, Raduan. Lavoura arcaica. Lisboa: Relógio D’Água, 1999.

TOKLAS, Alice. O livro de cozinha de Alice B. Toklas. Trad. de Helena Londres. Consultoria editorial de Nina Horta. São Paulo: Companhia das Letras, 1996.

Recebido para publicação em 04/10/2013

Aprovado em 15/02/2014

\section{NOTAS}

1 Importante imaginar o efeito imagético dessa receita quando não se encontra quente. Trata-se de uma combinação de dobradinha, chouriço, presunto, toucinho, orelha, pé de porco, linguiça e feijão branco. Cria-se, como na feijoada brasileira, uma camada branca e gelatinosa de gordura, que difere, radicalmente, da apresentação do prato quando em temperatura adequada.

2 Principalmente no volume intitulado, no Brasil, como Imagens do pensamento (BENJAMIN, 2004).

3 Para aprofundamento do tema, conferir o posfácio, de minha autoria, ao romance de Nassar publicado em Portugal pela Relógio D’Água (SEDLMAYER, 1999), bem como o livro Ao lado esquerdo do pai (SEDLMAYER, 1997). 